\title{
Doscientos años del Poder Judicial bonaerense
}

\author{
Two bundred years of the Buenos Aires Judicial \\ Power
}
Duzentos anos do Poder Judiciário de Buenos Aires

Deux cents ans du pouvoir judiciaire de Buenos Aires

布宜诺斯艾利斯两百年司法权

\author{
Diego Gabriel Presa ${ }^{1}$ \\ Universidad Nacional de La Plata, Argentina
}

Revista Derechos en Acción ISSN 2525-1678/ e-ISSN 2525-1686

Año 6/No 19 Otoño 2021 (21 marzo a 20 junio), 261-283

DOI: https://doi.org/10.24215/25251678e517

Recibido: 01/11/2020

Aprobado: 15/01/2021

Resumen: El presente trabajo recorre dos siglos de historia judicial bonaerense, desde su creación en 1821 a la actualidad. Podremos encontrar en las diferentes normas que se citan, el crecimiento del Poder Judicial de una de las provincias más importante de la Argentina y su consolidación en el tiempo, dividido en cinco etapas en el tiempo, con la idea de cumplir con la manda constitucional de afianzar la justicia.

Palabras clave: Poder Judicial Bonaerense, Suprema Corte de Justicia de Buenos Aires, doscientos años.

\footnotetext{
Abogado, profesor adjunto de Historia Constitucional Cat. III de la Facultad de Ciencias Jurídicas y Sociales de la UNLP, Relator de la Comisión de Asuntos Constitucionales y Justicia de la Honorable Cámara de Diputados de la Provincia de Buenos Aires. Email: dgpresa@ yahoo.com.ar (ORCID: https://orcid.org/0000-0003-3315-9301).
} 
Abstract: This work covers two centuries of Buenos Aires judicial history, from its creation in 1821 to the present. We can find in the different norms that are cited, the growth of the Judicial Power of one of the most important provinces of Argentina and its consolidation over time, divided into five stages in time, with the idea of complying with the constitutional mandate of secure justice.

Keywords: Buenos Aires Judicial Power, Supreme Court of Justice of Buenos Aires, two hundred years.

Resumo: 0 presente trabalho cobre dois séculos da história jurídica de Buenos Aires, desde sua criação em 1821 até o presente. Podemos encontrar nas diferentes normas que se citam, o crescimento do Poder Judiciário de uma das mais importantes províncias da Argentina e sua consolidação ao longo do tempo, dividido em cinco etapas no tempo, com o objetivo de cumprir o mandato constitucional de justiça segura.

Palavras-chave: Poder Judicial de Buenos Aires, Corte Suprema de Justiça de Buenos Aires, duzentos anos.

Résumé: Le présent travail couvre deux siècles d'histoire judiciaire de Buenos Aires, de sa création en 1821 à nos jours. On retrouve dans les différentes normes qui sont citées, la croissance du pouvoir judiciaire de l'une des provinces les plus importantes d'Argentine et sa consolidation au fil du temps, divisée en cinq étapes dans le temps, avec l'idée de se conformer au mandat constitutionnel de justice sécurisée.

Mot-clés: Pouvoir judiciaire de Buenos Aires, Cour suprême de justice de Buenos Aires, deux cents ans.

摘要：目前的工作涵盖了从1821年创建到现在的布宜诺斯艾利斯两 个世纪的司法历史我们可以在引用的不同规范中找到阿根廷最重 要省份之一的司法权的增长及其随时间的巩固分为五个阶段其思 想是遵守宪法规定公正的正义.

关键字：布宜诺斯艾利斯最高法院司法权，布宜诺斯艾利斯，已有 200年的历史. 


\section{Presentación}

El presente trabajo recorre dos siglos de historia judicial bonaerense, desde su creación en 1821 a la actualidad. Podremos encontrar en las diferentes normas que se citan, el crecimiento del Poder Judicial de una de las provincias más importante de la Argentina y su consolidación en el tiempo, dividido en cinco etapas en el tiempo, con la idea de cumplir con la manda constitucional de afianzar la justicia.

\section{Los primeros tiempos 1820-1854}

La Republica Argentina a partir de 2010 se ha convertido en un país bicentenario, y así también llegan a ese aniversario distintas instituciones, pero fundamentalmente poderes de los Estados Provinciales que componen la Nación.

La Provincia de Buenos Aires cumplió sus doscientos años en 2020, pero el Poder Judicial lo hace en el 2021, han transcurridos dos siglos y la Provincia jamás ha dejado de buscar, tal como lo establece y mantiene en su preámbulo la última reforma constitucional provincial de “... afianzar la justicia..." el objetivo que debe renovarse día a día para poder afianzar la justicia realmente y que esta pueda llegar a los bonaerenses en tiempo y forma.

La Sala de Representantes creada el 16 de febrero de 1820, dio el primer paso al dictar una ley de supresión de la autoridad de los Cabildos el 24 de diciembre de 1821, fecha que debemos tomar formalmente como el de inicio de la justicia provincial, antes de ella, en el primer periodo de formación de la Nación, entre 1810 a 1820, la justicia es de carácter nacional, pero a partir de la primer batalla de Cepeda $^{2}$ y el nacimiento de la Provincia de Buenos Aires, la justicia considerada como

\footnotetext{
$21^{\circ}$ de febrero de 1820, batalla entre las fuerzas de Entre Ríos y Santa Fe, Provincias bajo el protectorado de José Gervasio de Artigas contra las fuerzas del Directorio, a cargo del Director Supremo José Rondeau.
} 
nacional, queda en territorio de la nueva Provincia y comienza su organización como provincial.

La supresión del Cabildo como autoridad tenía varias motivaciones, para el Poder Ejecutivo, primero el Cabildodejaba de tener una autoridad que muchas veces parecía hasta superior, suplantándolo ante un vacío de poder, para el sistema republicano en sí mismo, se asumía una verdadera división de poderes y se abandonaba el viejo sistema español de funciones cruzadas con distintos poderes -ejecutivo, legislativo y judicialen un solo organismo, pero fundamentalmente el nuevo Poder Judicial, surgía una nueva estructura netamente jurídica, cimentada en jueces de primera instancia con carácter letrado, con inamovilidad en sus funciones y rentados, siendo la otra base la justicia de paz lego, confiada al vecino más respetado de una pequeña comunidad.

La justicia letrada tenía un gran inconveniente en todo el país, que era la falta de abogados que ocuparan los cargos de jueces, además estos abogados debían estar preparados en el conocimiento de la dispersa legislación existente, dado que se seguía utilizando la legislación indiana para la resolución de conflictos. No obstante se designaron dos jueces en la Capital -actual Ciudad de Buenos Aires- y tres jueces en la campaña -en el interior de la Provincia-, La Sala de Representantes autorizo por ley al gobernador Martin Rodríguez ${ }^{3}$ a dividir la Provincia en Departamentos Judiciales. Los jueces serían acompañados para poder desarrollar su labor por la Defensoría de Pobres y Menores, que tendría la función al mismo tiempo de Procuración General. El 13 de febrero de 1822 surgieron los oficiales de justicia que reemplazaban a los aguaciles mayores del antiguo cabildo.

La única Universidad hasta 1820 era la de Córdoba y Universidad Mayor, Real y Pontificia de San Francisco Xavier de

3 1771-1845, político y militar argentino, lucho en la guerra de la independencia y fue gobernador de Buenos Aires entre 1820 a 1824. 
Chuquisaca $^{4}$, la cual estaba bajo control realista, será liberada del yugo español en recién en diciembre de 1824 con la Batalla de Ayacucho, que terminaría con el poder realista en Sudamérica, aunque dicho hecho bélico, llevaría a la creación de un nuevo estado denominado Bolivia en honor a Simón Bolívar ${ }^{5}$, perdiendo las Provincias Unidas una de sus universidades.

En 1821 se crea por la Provincia, la Universidad de Buenos Aires que desarrollaría la carrera de abogado posibilitando el egreso de los mismos para un estado que los necesitaba, la carrera duraba unos seis años.

La nueva provincia sufrirá un duro golpe ante la ambición del grupo rivadaviano, quien la disuelve en 1826 con la sanción de la ley de capital sancionada por el Congreso de 1824 a 1827, y volverá a resurgir con la ley del 3 de julio de 1827, que insto a su organización nuevamente impulsado por Vicente López y Planes ${ }^{6}$, quien luego de ello, renunciaría la presidencia provisoria y se disolverá el Congreso 1824-1827 motu propio, desapareciendo la autoridad nacional. Así la Sala de Representantes repuesta en sus funciones, elegirá y designara a Manuel Dorrego $^{7}$ como nuevo gobernador. Mientras gobernó Juan Manuel de $\operatorname{Rosas}^{8}$ la justicia tuvo un papel secundario, la suma del poder público en el gobernador así lo había determinado en los hechos.

\footnotetext{
4 Actual ciudad de Sucre ubicada en la Republica Plurinacional de Bolivia.

5 1783-1830, militar y político venezolano, Presidente de la Gran Colombia entre 1819 a 1830, libertador de Venezuela, Colombia, Ecuador, completo la campaña del Perú iniciada por San Martin y Sucre que integraba su ejército libero Bolivia.
}

6 1784-1856, abogado, escritory político argentino, autor de la letra del Himno Nacional Argentino, gobernador de Buenos Aires en 1852.

7 1787-1828, militar y político argentino, uno de los fundadores del Partido Federal bonaerense, lucho en la guerra de la independencia, fue gobernador de Buenos Aires en 1820 y entre 1827 a 1828, murió fusilado por el General Juan Lavalle.

8 1793-1877, militar y político argentino, fue Gobernador de Buenos Aires entre 1829 a 1832 y entre 1835 a 1852, derrotado en la Batalla de Caseros se exilió en el Reino Unido hasta su muerte. 
La derrota de Rosas en Caseros $^{9}$, la organización de la Provincia bajo la tutela del nuevo caudillo Justo José de Urquiza ${ }^{10}$, daría una nueva composición heterogénea a la Sala de Representantes, los distintos conflictos entre ambos llevaron a la secesión de la Provincia de Buenos Aires de las trece Provincias hermanas, agrupadas ahora en la Confederación Argentina y por otro lado el Estado de Buenos.

\section{Etapa de constitucionalización 1854-1875}

El 11 de abril de 1854 el Estado de Buenos Aires sancionó su primera constitución provincial, donde el Poder Judicial tenía su propia sección que era la Sexta, en la cual se regulaba entre los artículos 118 a 129 el funcionamiento del mismo.

Establecía su independencia de cualquier otro poder (art. 118); seriadesempeñado por los tribunales y juzgados que la ley designe,siendo sus miembros inamovibles sin causa o sentencia legal (art. 119); para ser miembro del Tribunal Superior de Justicia, se requería estar en ejercicio de la ciudadanía, ser mayor detreinta años, con seis al menos de ejercicio en la profesión, en cambio para los llamados juzgados inferiores, bastarán dos años de profesión y veintey cinco de edad, con la misma calidad de ciudadano (art. 120).

El nombramiento de los jueces del llamado Tribunal Superior de Justicia, era por designación del gobernador a propuesta en terna del Senado, en cambio la de los juzgados inferioresera a propuesta en terna del tribunal superior (art. 121); en ambos casos gozaban de una compensación económica.

La Constitución fijaba la forma de fundar las sentencias, estableciendo un orden basado en el texto expreso de la ley, o

9 El 3 de febrero de 1852, batalla de Caseros entre las tropas de Juan Manuel de Rosas y Justo José de Urquiza, siendo este último el triunfador

10 1801-1870, militar y político argentino, gobernador de la provincia de Entre Ríos entre 1842 a 1852; 1860 a 1864 y 1868 a 1870, Presidente de la Confederación Argentina entre 1854 a 1860. 
en los principios o doctrinas de la materia (art. 124); El Tribunal Superior de Justicia tenía las facultades de superintendencia (art. 125). Además, la Carta Magna Provincial, autorizaba a cualquiera del pueblo a acusar a los miembros del poder judicial, por los delitos de cohecho, prevaricato, procedimientos injustos contra la libertad de las personas, contra la propiedad y seguridad de domicilio (art. 128). Determinaba una jurisdicción especial para las llamadas causas contenciosas en materia de hacienda, y las que nacen de contratos entre particulares y el gobierno, las atribuciones y formas de ese tribunal serian establecidas por ley (art. 129).

La unión de Buenos Aires a la Confederación Argentina por el Pacto del 11 de noviembre de 1859, conocido como San José de Flores, llevara a una reforma del texto constitucional de 1854 , que se producirá en 1873 , mediante ley $634^{11}$ de la Legislatura Provincial.

En principio, la Constitución Provincial de 1873, cambia la denominación de la Corte Provincial, se reemplaza la de Tribunal Superior de Justicia por el actual de Suprema Corte de Justicia.

El Poder Judicial se encontraría ahora en la Sección Quinta a partir de los artículos 155 al 198, divida en tres capítulos.

El Capítulo I, establecía el nuevo nombre de la Corte y por debajo de ella se encontraban, las Cámaras de Apelación y demás Tribunales, jueces y jurados.

Las atribuciones de la Suprema Corte de Justicia Provincial eran reguladas en el artículo 156, podemos distinguir las siguientes:

$1^{\circ}$. Ejercía la jurisdicción originaria y de apelación, para conocer y resolver acerca de la constitucionalidad o inconstitucionalidad de leyes, decretos o reglamentos sobre materia regida por la Constitución, y que fuera cuestionada por el propio interesado.

\footnotetext{
11 Sancionada y promulgada el 23 de febrero de 1870.
} 
$2^{\circ}$. La Corte conocía y resolvía originaria y exclusivamente en causas de competencia entre los poderes públicos de la Provincia y las suscitadas entre los tribunales por su jurisdicción.

$3^{\circ}$. Se le otorgaba la jurisdicción en las causas contenciosoadministrativas, en única instancia, previa negativa de la administración, una ley determinaría los plazos dentro del cual se deduciría la acción y los procedimientos.

$4^{\circ}$. Conocía en consulta o en grado de apelación, sobre las causas en que se imponga la pena capital o de muerte, para decidir, si la ley en que se funda la sentencia es o no aplicable al caso, requiriendo unanimidad para declararla aplicable o no.

$5^{\circ}$. Conoce y resuelve en grado de apelación de la aplicabilidad de la ley, en que los tribunales de justicia, en última instancia, fundan su sentencia.

La Presidencia de la Corte era en forma anual, comenzaba con el miembro de mayor edad, podía establecer su propio reglamento (arts. 157 y 158). Tenía la obligatoriedad de informar anualmente una memoria al Poder Legislativo, sobre el estado de la administración de justicia

En cuanto a las Cámaras de Apelación, Tribunales o Jueces de primera instancia civil y comercial, encargaba a la Legislatura determine los límites de su jurisdicción y las materias de acuerdo al fuero (art. 160), se autorizaba a instrumentar el juicio por jurado, pudiendo asimismo a la Legislatura a limitarlo en caso de que no sea viable.

La obligatoriedad de fundar los votos en las sentencias, comenzando por el juez que fuera insaculado ${ }^{12}$, la publicidad de los procedimientos, el establecimiento de un libro de sentencias, la libre defensa y representación ante los tribunales, eran objetivos que plasmaba el nuevo texto constitucional.

\footnotetext{
12 Poner en un saco, urna u otro recipiente papeletas o bolas con números o con nombres de personas o cosas, para ser sorteados, insacular es sortear.
} 
En cuanto a la Justicia Penal o llamada en lo criminal, se establecía el método de jurados, un jurado para aceptar o no la acusación y el segundo jurado para determinar si es culpable o inocente el acusado (art. 174).

Las sentencias debían ser fundadas en el texto expreso de la ley, y a falta de éste, en los principios jurídicos de la legislación vigente en la materia respectiva, y en defecto de éstos en los principios generales del derecho, teniendo en consideración las circunstancias del caso (art. 176).

La Justicia de Paz que venía desarrollándose en la Provincia desde su nacimiento como tal, era establecida en todo su territorio, a cargo de ciudadanos mayores de 25 años, contribuyentes, con dos años de residencia en el distrito a ser designados y que sepan leer y escribir, siendo legos (art. 179). Eran elegidos por los electores. Entendían en un procedimiento que era verbal y actuado, las causas eran las denominadas de menor cuantía y el cargo lo ejercía alguien respetado de la comunidad que pudiera actuar como un mediador, para componer las cosas o esclarecer los hechos sucedidos.

Un cambio trascendental en 1873, fue que los jueces de paz, pasaron a ser funcionarios judiciales, dejando de ser simple funcionarios municipales, y estos jueces eran elegidos por electores calificados, con el intento de crear jueces elegidos por el pueblo, este llevaría a un límite al propio Poder Ejecutivo Provincial, quien hasta ese momento nombraba a los jueces de paz, el ser elegidos evitaría que estos jueces estuvieran influenciados por la política dando un servicio de justicia imparcial.

En el capítulo II, quedaba regulada la elección, duración y responsabilidad de los miembros del Poder Judicial. Los jueces que eran letrados los elegía el Poder Ejecutivo con acuerdo del Senado y duraban en su cargo mientras dure su buena conducta (arts. 184 y 185).

Entre los requisitos (art. 186) para ser designado Juez de la Suprema Corte de Justicia se requería ciudadanía en ejercicio, título o diploma de abogado, treinta años de edad y menos de 
setenta y seis años en el ejercicio en la profesión de abogado, en cambio para las cámaras de apelación bastarán cuatro años. En el caso de los jueces de primera instancia, se exigía veinticinco años de edad (art. 187).

El artículo 190 reglaba el jury de enjuiciamiento que sería integrado por siete diputados y cinco senadores profesores de derecho, a falta de estos los letrados que tengan las condiciones para ser electos senadores. El juez acusado quedaba suspendido en el cargo desde que el jury admitía la acusación, el veredicto del jury era por culpable o no (arts. 191 y 192).

El capítulo III, nos habla de Tribunales Militares, recordemos que en ese momento la Provincia de Buenos Aires y las demás Provincias también contaban con milicias y/o guardias nacionales, comprendía tanto a las fueras de mar y tierra.

Dejaba librado a la Legislatura que determine los delitos o faltas a penar.

La constitución regulaba en sus declaraciones derechos y garantías, el juicio por jurado (art. 14), y el habeas corpus (art. 17).

La elección popular de los jueces de paz, nunca llego a materializarse, tanto la Legislatura como el Poder Ejecutivo, entraron en un verdadero conflicto de poderes, que fue sometido a consideración de la Suprema Corte Provincial, pero tanto las leyes posteriores que regularían al Poder Judicial y sus funcionarios como la reforma de 1889 del texto Constitucional Provincial, permitirán el nombramiento de estos jueces por el Pode Ejecutivo a propuesta de una terna elevada por el municipio respectivo.

\section{Organización actual del Poder Judicial 1875-1955}

La Suprema Corte se instaló en 1875, sus primeros ministros fueron Manuel María Escalada ${ }^{13}$, Sixto Villegas ${ }^{14}$, Alejo Buenaventura

\footnotetext{
13 1823-1896, abogado, político y juez de la Suprema Corte de Justicia en 1875 hasta 1884, previamente ocupo diversos cargos tanto en el Poder Ejecutivo como en el Legislativo.

14 1831-1881, abogado y político argentino, fue nombrado juez de la SCBA en 1875.
} 
González Garaño ${ }^{15}$, Sabiniano Kier ${ }^{16}$ y Andrés Somellera ${ }^{17}$, por Acordada $2 / 1875^{18}$ la Corte dicto su propio reglamento y se reservó dictar el de las Cámaras de Apelaciones.

Previamente en 1874 , se había dictado la ley $888^{19}$, la cual autorizaba con carácter provisorio mientras no hubiera una ley orgánica del Poder Judicial, que el Ministerio Publico Fiscal, sea desempeñado en el departamento de la Capital por un Procurador General de la Suprema Corte, con un fiscal de las cámaras de apelación, dos agentes fiscales en lo Civil y uno en lo Criminal. En los otros Departamentos habría un agente fiscal en lo Civil y Criminal para ambas instancias.

Seguidamente se dictó la ley $889^{20}$ ordenando en su funcionamiento el Ministerio de Pobres y Menores -actuales defensorías-.

En lo que respecta a los Departamentos Judiciales, habían sido organizados primigeniamente por la ley $112^{21}$, estableciendo la división de la campaña en tres departamentos judiciales, del Norte, Centro y Sud. La ley $1319^{22}$ los reorganizaría en: de la Capital, con dos Cámaras de Apelación en lo civil y una para lo criminal y comercial; y en el interior, tres Cámaras de Apelación, ubicadas en los denominados Departamentos Judiciales del Sud, del Centro y del Norte, con jurisdicción civil, comercial y criminal, su sede será en las ciudades de Dolores, Mercedes y San Nicolás.

La ley $1431^{23}$ estableció finalmente la primera ley Orgánica del Poder Judicial, la cual ratificaba a la Corte como tal y los

\footnotetext{
15 1833-1890, abogado, político y juez de la Suprema Corte de Justicia entre 1875 a 1884.

16 1832-1912, abogado, político, juez de la Suprema Corte de Justicia de la Provincia de Buenos Aires entre 1875 a 1885 y Procurador General de la Nación de Argentina.

17 1809-1881, abogado, político y juez de la Suprema Corte de Justicia.

18 Acordada del 26 de enero de 1875.

19 Sancionada el 22 de junio y promulgada el 30 de junio de 1874.

20 Sancionada el 22 de junio y promulgada el 30 de junio de 1874.

21 Sancionada el 20 de octubre y promulgada el 24 de octubre de 1856.

22 Sancionada el 30 de octubre y promulgada el 30 de noviembre de 1879.

23 Sancionada el 25 de octubre y promulgada el 26 de octubre de 1881.
} 
Departamentos Judiciales existentes, la Defensoría de Menores quedaba a cargo de un Defensor General de Menores de toda la Provincia.

En 1884, la Suprema Corte dicto la Acordada $159^{24}$, por la cual se declaraba clausurados los Tribunales del Departamento Judicial de la Capital de la Provincia en la ciudad de Buenos Aires y suspendidos los términos judiciales hasta el 30 de abril de 1884. Se ordenaba el traslado a la Ciudad de La Plata donde sería su nueva y definitiva sede, a tal efecto se suspendían los términos procesales. La ciudad de La Plata, había sido fundada el 19 de noviembre de 1882, reemplazando a la ciudad de Buenos Aires como nueva capital provincial.

En 1886 la Suprema Corte ocupara el actual palacio ubicado en calle 13 entre 47 y 48 en la ciudad de La Plata.

La necesidad de contar con un archivo de causas, lleva a la Legislatura a pedido del Poder Judicial a sancionar la ley $1932^{25}$, creando en un comienzo "Archivo General de los Tribunales del Departamento de la Capital", contaría con la documentación de: los protocolos de todas las escribanías de registro existentes en el Departamento de la Capital, exceptuando los del último año, y con los expedientes archivados en las secretarias y demás oficinas de actuación de la Capital, entraría en funciones el 1 de junio de $1889 .{ }^{26}$

En 1889 con la ley $1419^{27}$ se estableció la necesidad de reforma de la Carta Magna Provincial pero las reformas no modificaron el régimen judicial.

\footnotetext{
24 Acordada del 14 de abril de 1884.

25 Sancionada el 14 de octubre y promulgada el 18 de octubre de 1887.

26 NUÑEZ, Roberto Daniel (2018). ' 'Los archivos del Poder Judicial de la Provincia de Buenos Aires. De la visión civilista y patrimonial a la protección de los Derechos Humanos" en Revista Hilos Documentales, Año 1, Nro. 1, pp. 1-12. Disponible en https://revistas.unlp.edu. ar/HilosDocumentales/article/view/6031/5331.

27 Sancionada el 22 de agosto y promulgada el 24 de agosto de 1881.
} 
Siguiendo un orden cronológico en el tiempo en 1902 se dicta ley $2795^{28}$ que crea el Departamento Judicial de Costa Sur, con asiento en la ciudad de Bahía Blanca.

La ley $3617^{29}$ establece un nuevo Departamento Judicial llamado Sudoeste con asiento en la ciudad de Azul. La ley $3880^{30}$ creara en cada uno de los Departamento Judiciales el Archivo correspondiente.

En 1934 la ley $4209^{31}$ declaro la necesidad de reforma de la Constitución Provincial de 1889, y en cumplimiento del artículo 217 del texto constitucional llamo a votar por sí o no por la reforma declarada. Aprobada la necesidad de reforma se dictó la ley $4219^{32}$ convocando a la elección de convencionales constituyentes.

La nueva Constitución de 1934 regulo el Poder Judicial en su Sección Quinta, con un primer Capítulo que comenzaba por definir quien desempañaba dicho poder, el cual quedaba a cargo de una Suprema Corte de Justicia, y por debajo de ella las Cámaras de Apelación, Jueces y demás Tribunales que la ley establezca (art. 148).

En el Capítulo II, establecía las atribuciones de la Suprema Corte de Justicia, ejerciendo la jurisdicción originaria y de apelación, conociendo y resolviendo la constitucionalidad o inconstitucionalidad de leyes, decretos, ordenanzas o reglamentos sobre materia regida por la Constitución y que sea controvertida por parte interesada.

Además, conocía originaria y exclusivamente en las causas de competencia entre los poderes públicos de la Provincia y en las que se susciten entre los tribunales de justicia.

\footnotetext{
28 Sancionada el 7 de mayo y promulgada el 21 de mayo de 1902.

29 Sancionada el 27 de agosto y promulgada el 2 de septiembre de 1915.

30 Sancionada el 26 de octubre y promulgada el 2 de noviembre de 1926.

31 Sancionada el 2 de febrero y promulgada el 5 de febrero de 1934.

32 Sancionada el 6 de julio y promulgada el 11 de julio de 1934.
} 
Se le otorgaba la competencia en las causas contencioso-administrativas en única instancia y en juicio pleno, competencia que se encontraba regulada por la ley $2961^{33}$, llamada Código Varela.

En materia de recursos, conocía y resolvía en grado de apelación: a) en los Recursos de la Aplicabilidad de la Ley, en que los tribunales de justicia en última instancia, funden su sentencia y b) Recursos de nulidad contra las sentencias definitivas pronunciadas en última instancia por los tribunales de justicia.

La presidencia de la Corte se mantenía en formato anual (art.150) y se ratificaban atribuciones de superintendencia que ya poseía.

En el Capítulo III autorizaba a la Legislatura a establecer Cámaras de Apelación y Tribunales o Juzgados de Primera Instancia en lo civil, comercial y penal, determinando los límites de su jurisdicción territorial y las materias de su competencia.

Las sentencias serian fundadas en el texto expreso de la ley, y a falta de éste, en los principios jurídicos de la legislación vigente en la materia respectiva, y en defecto de éstos, en los principios generales del derecho, teniendo presentes las circunstancias dela causa (art. 159).

El Capítulo IV regulaba sobre la Justicia de Paz, autorizando a la Legislatura a establecer dichos juzgados en la Provincia, y citaba otros de menor cuantía. Los jueces de Paz serían los ciudadanos mayores de veinticinco años, con residencia de dos años en el distrito a ser designados, nombrados por el Poder Ejecutivo a propuesta en terna por las municipalidades.

En el Capítulo V se regulaba la elección, duración y responsabilidad de los miembros del poder judicial, dejando a los funcionarios letrados y procurador a ser nombrados por el Poder Ejecutivo con acuerdo del Senado (art. 165).

El Jury de enjuiciamiento (art. 172), quedaba compuesto por un jurado de once miembros, integrado por el presidente de la Suprema Corte de Justicia que lo presidirá, cinco abogados

33 Sancionada el 14 de diciembre y promulgada el 22 de diciembre de 1905. 
inscriptos en la matrícula que reúnan las condiciones para ser miembros de dicho tribunal, y hasta cinco legisladores abogados, designados por sorteo en acto público. El Juez acusado quedaba suspendido en el ejercicio de su cargo desde el día en que el jurado admitía la acusación. El Jurado solo se limitaba a declararlo culpable o no, en caso de delito se remitía al juez competente.

El artículo 180 hablaba del Ministerio Público, desempeñado por el Procurador General de la Suprema Corte de Justicia; los Fiscales de Cámaras, agentes fiscales, asesores de menores y defensores de pobres y ausentes, quedando las facultades de superintendencia a cargo del propio Procurador General.

La ley $5128^{34}$ establece en el escalafón del personal del Poder Judicial la bonificación por antigüedad en el cargo, en escalas que iban de cinco años en adelante y diferenciando su valor en administrativos y personal de servicios.

En 1947 se crean los Tribunales de Trabajo por ley $5178^{35}$, estableciendo además el procedimiento laboral.

\section{Consolidación del sistema judicial 1955 a 1983}

En 1955 se promulgo la ley $5827^{36}$ llamada ley Orgánica del Poder Judicial, que establece siete Departamentos Judiciales, en las ciudades de Eva Perón -actual La Plata-Mercedes, San Nicolás, Dolores, Azul, Bahía Blanca y de Mar del Plata. Establece el número de miembros de la Corte en siete jueces, se determina el quórum para funcionar como tal, se detallan sus atribuciones específicamente (art. 31), al igual que las atribuciones de las Cámaras y su funcionamiento, dentro del Capítulo IV, los jueces de primera instancia quedaban normados en el Capítulo V; los Tribunales Laborales en el Capítulo VI; los denominados

\footnotetext{
34 Publicada en el Boletín Oficial de la Provincia el 6 de marzo de 1947.

35 Publicada en el Boletín Oficial de la Provincia el 18 de noviembre de 1947.

36 Publicada en el Boletín Oficial de la Provincia el 13 de julio de 1955.
} 
Tribunales de Menores en el Capítulo VII; los Jueces Forenses en el Capítulo VIII; los Jueces de Paz en el Capítulo IX; por último se reglamentaba las alcaldías en el Capítulo XI.

En el Título III, se establecían las atribuciones de los magistrados y funcionarios de la administración de justicia.

El Titulo IV, se regulaba el Ministerio Publico, sus funciones (art. 76); los Fiscales de Cámara (art. 77); Agentes Fiscales (art. 78); Asesores de Incapaces (art. 79); Defensores de Pobres y Ausentes (art 80); Agentes Fiscales de Paz (art. 88) y Defensores de Incapaces de Paz (art. 91).

En el Título V, se encontraban las reparticiones auxiliares de la administración de justicia, como Martilleros Públicos; Tasadores, Traductores, Intérpretes, Calígrafos y Peritos en General.

El Archivo de los Tribunales se encontraba en el Titulo VI. En el Capítulo II de dicho título, se instrumentaba lo relacionado con destrucción o reducción de expedientes, El Registro Público de Comercio era comprendido en el Capítulo III; la Oficina Pericial era establecida en el Capítulo IV, la ley terminaba con disposiciones transitorias, entre otras su entrada en vigencia el 1 de enero de 1956.

En 1958 por ley $5924^{37}$ se creó el Departamento Judicial de Junín, asimismo en 1961 se amplían los Departamentos Judiciales mediante la ley $6615^{38}$ a un total de nueve, denominados: Departamento de La Plata, Departamento de Mercedes, Departamento de San Nicolás, Departamento de Dolores, Departamento de Azul, Departamento de Bahía Blanca, Departamento de Mar del Plata, Departamento de Junín y Departamento de San Isidro.

La ley $7079^{39}$ produjo una ampliación de los integrantes del máximo tribunal, pasaron de ser siete a nueve sus miembros.

37 Publicada en el Boletín Oficial de la Provincia el 12 de noviembre de 1958.

38 Publicada en el Boletín Oficial de la Provincia el 15 de noviembre de 1961.

39 Publicada en el Boletín Oficial de la Provincia el 28 de octubre de 1965. 
En 1970 y esta vez por decreto ley $7602 / 1970^{40}$ se amplían los Departamentos Judiciales a once en total, sumándose los Departamentos Judiciales de Trenque Lauquen y de Morón, por un nuevo decreto ley 7706/1971 ${ }^{41}$ se adicionara otro Departamento que será el número doce, llamado Departamento Judicial de San Martin, no obstante en julio de 1971se sumara el Departamento Judicial de Lomas de Zamora llegando a ser trece en total de acuerdo al decreto ley 7724/197142. En 1978 se produjo una modificación a la Justicia de Paz lega, que paso a ser letrada por medio del decreto ley $9229 / 1978^{43}$.

\section{Etapa democrática 1983 a hoy}

La vuelta a la democracia en 1983 y el restablecimiento de la Legislatura, posibilitaría el dictado de la ley $10374^{44}$ que estable un nuevo nomenclador de cargos, divididos en niveles, teniendo inicio la carrera judicial en el nivel 1, siendo el máximo el nivel 22 correspondiente a Juez de la Suprema Corte en ese momento, hoy con distintas modificaciones se ha ampliado al nivel 23 como máximo y niveles intermedios.

La ley $10470^{45}$ aumento nuevamente los Departamentos Judiciales, de trece a diecisiete, siendo los creados Necochea, Pergamino, Quilmes, y Zárate-Campana. Por medio de la ley $10486^{46}$ se produjo una modificación en el Ministerio Público, creando la figura del Subprocurador General de la Suprema Corte de Justicia.

\footnotetext{
40 Publicada en el Boletín Oficial de la Provincia el 23 de abril de 1970.

41 Publicada en el Boletín Oficial de la Provincia el 7 de Junio de 1971.

42 Publicada en el Boletín Oficial de la Provincia el 21 de Julio de 1971.

43 Publicada en el Boletín Oficial de la Provincia el 9 de enero de 1979.

44 Publicada en el Boletín Oficial de la Provincia el 29 de enero de 1986.

45 Publicada en el Boletín Oficial de la Provincia el 16 de enero de 1987.

46 Publicada en el Boletín Oficial de la Provincia el 20 de abril de 1987.
} 
En diciembre de 1988, la Suprema Corte dicto el llamado acuerdo 2300/88 que ha venido regulando hasta la fecha todo lo relativo al personal del Poder Judicial, denominado Estatuto del Agente Judicial, distinguiendo los agrupamientos 1) servicio; 2) obrero; 3) administrativo; 4) técnico y 5) profesional, estableciendo los requisitos de ingreso, promociones, cambios de agrupamientos y egreso del Poder Judicial, los derechos y obligaciones del personal, las retribuciones, subsidios, indemnizaciones, licencias, el régimen disciplinario.

De acuerdo a la ley $10812^{47}$ se crea el Departamento Judicial de La Matanza, elevándose el número a dieciocho departamentos.

La ley $11453^{48}$ creo los Tribunales de Familia de Instancia Única, además de producir una modificación al Código Procesal Civil y Comercial Provincial instaurando un nuevo proceso.

En 1993 la Legislatura sanciono la ley $11488^{49}$ que declaro la necesidad de reforma de la Constitución Provincial, la reforma, introdujo un nuevo artículo que fue el 20 del texto actual, regulando el recurso de habeas corpus, la garantía de recurso o acción de amparo y la acción de habeas data.

El Poder Judicial, pasó a estar normado en la Sección VI de la Carta Magna Provincial, una primera reforma que se produjo dentro de él, es la competencia contenciosa administrativa, que era originaria que quedaba a su cargo, paso a descentralizarse en juzgados y cámaras en la materia a designar.

Se reformulo el anterior artículo 151 -del texto de 1934- que paso a ser el artículo 163, en el cual se introdujo la fuerza u obligatoriedad de las sentencias tanto de la Suprema Corte de Justicia como de los restantes tribunales, la posibilidad de disponer de la fuerza pública para lograr su cumplimiento, fijando para las causas contenciosas administrativas un plazo de sesenta días

\footnotetext{
47 Publicada en el Boletín Oficial de la Provincia el 5 de octubre de 1989.

48 Publicada en el Boletín Oficial de la Provincia el 29 de noviembre de 1993.

49 Publicada en el Boletín Oficial de la Provincia el 17 de enero de 1994.
} 
para su cumplimiento, bajo responsabilidad de los empleados o funcionarios que retardaren la misma o se negaren a cumplirla.

El nuevo artículo 166, también fue adaptado a los nuevos tiempos con la creación de la Policía Judicial. Se contempló, además, la idea de una instancia de revisión judicial especializada en materia de faltas municipales. La creación de un cuerpo de magistrados suplentes, el cual dispone la Suprema Corte de Justicia para cubrir vacantes transitorias.

Los casos originados por la actuación u omisión de la Provincia, los municipios, los entes descentralizados, y otras personas, en el ejercicio defunciones administrativas, paran a ser juzgados por tribunales competentes en lo contencioso administrativo, de acuerdo a los procedimientos que determine la ley, la que establecerá los supuestos en que resulte obligatorio agotar la vía administrativa.

El Capítulo IV, asignado a la Justicia de Paz, el artículo 172 establece la instalación de dichos juzgados en todos los distritos que no sean cabecera de Departamento Judicial. Igualmente, para las causas de menor cuantía y vecinales, el nuevo artículo 174, prevé que la ley establecerá, un procedimiento predominantemente oral, que garantice la inmediatez, informalidad, celeridad, accesibilidad y economía procesal, procurando la conciliación de las partes.

El Capítulo V, el artículo 175, en lo que respecta a la designación de los jueces, no modifica la forma en los jueces de la Suprema Corte, pero si los de instancias inferiores, que quedan a cargo del nuevo organismo que es el Concejo de la Magistratura Provincial, el cual, mediante concurso público de oposición y antecedentes, seleccionará una terna que elevará al Poder Ejecutivo y este requerirá el acuerdo del Senado

El Consejo de la Magistratura, fue establecido por la ley $11868^{50}$, cuya sede es en la ciudad de La Plata, está compuesto

50 Publicada en el Boletín Oficial de la Provincia el 3 de diciembre de 1996. 
en forma equilibrada por representantes de los poderes Ejecutivo y Legislativo, de los jueces de las distintas instancias y de la institución que regula la matrícula de los abogados en la Provincia. Cuenta con un mínimo de dieciocho miembros, duran en sus cargos cuatro años y se renuevan por mitades cada bienio.

El Consejo será presidido por el presidente de la Suprema Corte de Justicia y estará compuesto por dicho magistrado; un (1) juez de Cámara; un (1) juez de primera o única instancia y un (1) miembro del Ministerio Público; seis (6) representantes del Poder Legislativo; cuatro (4) representantes del Poder Ejecutivo y cuatro (4) representantes del Colegio de Abogados de la Provincia.

Sancionada la nueva Constitución Provincial, las normas que complementaron la ley orgánica, así como las modificaciones legales de carácter procesal fueron numerosas, algunas de ellas fueron, una reforma introducida mediante la ley $11982^{51}$ estableció el Tribunal de Casación Penal, integrado por diez miembros, divididos en una presidencia y tres salas de tres miembros cada una, con competencia en todo el territorio provincial.

En 1998 se crea el fuero contencioso administrativo por ley $12074^{52}$ derogándose el llamado código Varela de principios del siglo XX, la Legislatura dicto al efecto la ley $12008^{53}$, por tal motivo, la Corte, de acuerdo a la reforma constitucional de 1994, dejo su competencia en esta materia. Por ley $13601^{54}$ se crea el Departamento Judicial de Moreno-General Rodríguez, llegando a diecinueve los departamentos en toda la Provincia.

La ley $13634^{55}$ crea en su título III, el Fuero de la Responsabilidad Penal Juvenil y transforma los Tribunales de Familia

\footnotetext{
51 Publicada en el Boletín Oficial dela Provincia el 31 de julio de 1997.

52 Publicada en el Boletín Oficial de la Provincia el 26 de enero de 1998.

53 Publicada en el Boletín Oficial de la Provincia el 3 de noviembre de 1997.

54 Publicada en el Boletín Oficial de la Provincia el 29 de diciembre de 2006.

55 Publicada en el Boletín Oficial de la Provincia el 2 de febrero de 2007.
} 
en juzgados unipersonales. A su vez la ley $13662^{56}$ estableció el número de miembros de la Suprema Corte en siete, estableciendo su disminución de nueve miembros a los establecidos por el transcurso del tiempo.

La ley $13837^{57}$ creo el Cuerpo de Magistrados Suplentes, el cual dispone la Suprema Corte de Justicia, para cubrir vacantes transitorias, considerando a tales, la falta de cobertura temporaria del cargo de magistrado por renuncia, remoción, suspensión en los términos del artículo 183 de la Constitución Provincial, fallecimiento o licencia por un plazo de más de sesenta días corridos. La ley $13859^{58}$ crea del Departamento Judicial de Merlo, llegando a veinte en todo el territorio provincial, aunque el mismo sigue subsumido dentro del Departamento Judicial de Morón. También por ley $14484^{59}$ estableció el Departamento Judicial de Avellaneda-Lanús, entrando en funciones en octubre de 2020, llegando a los veintiún departamentos actuales.

En el año 2002, fue designada la primera mujer como integrante de la Suprema Corte de Justicia, la Dra. Hilda Kogan, quien ha presidido nuestro máximo tribunal en los periodos 2010-2011 y 2017-2018.

Los demás integrantes son el Dr. Eduardo Pettigiani, quien fue designado en 1996; el Dr. Luis Genoud, designado en el año 2002; el Dr. Daniel Soria, designado en el año 2002, el Dr. Eduardo de Lazzari, quien ingreso en el tribunal en el año 1997 y el Dr. Sergio Torres designado en el año 2019.

Actualmente por fallecimiento del Dr. Héctor Negri en enero de 2020 y el retiro del Dr. Eduardo De Lazzari en los primeros meses de 2021, se encuentran dos vacantes sin cubrir, el Dr. Negri, había sido designado en 1983, cuando retorno la democracia.

\footnotetext{
56 Publicada en el Boletín Oficial de la Provincia el 26 de abril de2007.

57 Publicada en el Boletín Oficial de la Provincia el 18 de julio de 2008.

58 Publicada en el Boletín Oficial de la Provincia el 9 de septiembre de 2008.

59 Publicada en el Boletín Oficial de la Provincia el 25 de Febrero de 2013.
} 


\section{Conclusión}

En doscientos años la justicia bonaerense ha crecido de tres departamentos judiciales a diecinueve en pleno funcionamiento y dos con plazos para su establecimiento, una ley orgánica que ha cumplido 65 años, con intensas reformas para ser actualizada, reformas de carácter estructural que han dotados de juzgados de paz en todas las ciudades que no son cabecera de Departamento Judicial, de jueces de primeras instancias y diversidades de Cámara de Apelaciones en distintas materias, un Tribunal de Casación Penal, el Ministerio Publico, encabezado por el Procurador General, dicho Ministerio, necesitaría una reforma legal, para separar al Ministerio Publico de la Defensa del Ministerio Publico Fiscal, entendiéndose que el funcionario que es jefe de los fiscales, no puede serlo de los defensores al mismo tiempo, hay un conflicto en los intereses que representa, sería como jugar solo al ajedrez solo y pensar los movimientos de ambos lados.

Al mismo tiempo se han dictado códigos procesales civiles, penales, contenciosos administrativos, laborales, de familia, tributarios, de fueros juveniles e infinidad de otras leyes que complementan el sistema judicial. Ha crecido junto con el sistema judicial la colegiación de abogados por medio de los Colegios Profesionales y una Federación Argentina de Colegios Abogados, con jurisdicción en todo el país, en la Provincia de Buenos Aires la ley $5177^{60}$ regula la profesión de abogado, siendo este un auxiliar y/o colaborador de la justicia y a quien en el desempeño de su profesión es asimilado a los magistrados en cuanto atañe al respeto y consideración que debe guardársele (art. 56).

Se expresa constantemente que la Justicia tardía es la máxima injusticia, para romper esta frase tan cruel, debemos redoblar el esfuerzo, pero no solamente por parte del Poder Judicial, de los letrados o demás colaboradores e interlocutores

60 Sancionada el 28 de octubre y promulgada el 6 de noviembre de 1947. 
del sistema, sino también el compromiso del Poder Ejecutivo y del Poder Legislativo en producir una estructura acorde a los nuevos tiempos.

Las estadísticas, nos muestran que por ejemplo elevar una causa a juicio oral y público en el sistema penal, después de producida la investigación penal preparatoria, no es menor a un plazo de dos años a contar desde el día que se pide su elevación, es decir, la audiencia que el pueblo espera, con el juez, el fiscal de juicio, los abogados defensores y el jurado, recién puede llevarse adelante dentro de dos años, llevándonos a la conclusión de la necesidad de más estructura judicial, más personal y diré que la creación y descentralización a través de más Departamento Judiciales, muchos esgrimirán la gastada frase "no hay presupuesto para eso" pues tendremos que buscarlo, porque es necesario para llevar Justicia a las personas que lo requieren y peticionan.

Más allá de estas reflexiones que como letrado y operador del sistema uno puede expresar, celebremos lo conseguido hasta hoy, no solo festejemos los doscientos años, sino que recordemos y conmemoremos a todas y todos los que han dado hasta su vida, por la mejora del sistema y seguir haciendo $\mathrm{y}$ llevando la justicia adelante. 